\title{
Effectiveness of conservative treatments for the lumbosacral radicular syndrome: a systematic review
}

\author{
Pim A. J. Luijsterburg • Arianne P. Verhagen • \\ Raymond W. J. G. Ostelo • Ton A. G. van Os • \\ Wilco C. Peul · Bart W. Koes
}

Received: 20 May 2006/Revised: 3 January 2007/ Accepted: 10 March 2007/Published online: 6 April 2007

(C) Springer-Verlag 2007

\begin{abstract}
Patients with a lumbosacral radicular syndrome are mostly treated conservatively first. The effect of the conservative treatments remains controversial. To assess the effectiveness of conservative treatments of the lumbosacral radicular syndrome (sciatica). Relevant electronic databases and the reference lists of articles up to May 2004 were searched. Randomised clinical trials of all types of conservative treatments for patients with the lumbosacral radicular syndrome selected by two reviewers. Two reviewers independently assessed the methodological quality and the clinical relevance. Because the trials were considered heterogeneous we decided not to perform a meta-analysis but to summarise the results using the rating system of levels of evidence. Thirty trials were included that evaluated injections, traction, physical therapy, bed
\end{abstract}

P. A. J. Luijsterburg $(\bowtie) \cdot$ A. P. Verhagen .

Ton A. G. van Os - B. W. Koes

Erasmus MC, General Practice, PO Box 1738,

3000 DR Rotterdam, The Netherlands

e-mail: pimluijsterburg@home.nl

R. W. J. G. Ostelo

Institution for research in Extramural Medicine

(EMGO), Amsterdam University Medical Center,

Amsterdam, The Netherlands

R. W. J. G. Ostelo

Amsterdam School of Allied Health Education,

Amsterdam, The Netherlands

W. C. Peul

Neurosurgery, Leids University Medical Center, Leiden, The Netherlands

W. C. Peul

Neurosurgery, Medical Center Haaglanden,

Den Haag, The Netherlands rest, manipulation, medication, and acupuncture as treatment for the lumbosacral radicular syndrome. Because several trials indicated no evidence of an effect it is not recommended to use corticosteroid injections and traction as treatment option. Whether clinicians should prescribe physical therapy, bed rest, manipulation or medication could not be concluded from this review. At present there is no evidence that one type of treatment is clearly superior to others, including no treatment, for patients with a lumbosacral radicular syndrome.

Keywords Conservative treatment - Lumbosacral radicular syndrome $\cdot$ Randomised clinical trial - Sciatica . Systematic review

\section{Background}

The lumbosacral radicular syndrome (LRS), also called sciatica, is a disorder with radiating pain in one or more lumbar or sacral dermatomes, and can be accompanied by phenomena associated with nerve root tension or neurological deficits [26, 27, 34, 43]. A prolapsed disc mostly causes LRS, but other causes include spinal or lateral recess stenosis, tumours or radiculitis [13, 34]. The incidence of LRS in general practice in the Netherlands is estimated between 60,000 and 75,000 a year [13].

Most patients with LRS are treated conservatively in the first 6-12 weeks (acute and subacute phase) [34]. However, the effectiveness of most of the conservative interventions has not yet been demonstrated beyond doubt. The review of Vroomen et al. [40] about conservative treatment of sciatica showed the lacking of evidence either for or against the efficacy of traction, exercise therapy or drug therapy for the management of LRS. They reported that epidural steroids 
might be beneficial for subgroups of nerve root compression. Vroomen et al. searched literature between 1966 and March 1998. Several new RCTs have been published since, so an updated review on the whole spectrum of conservative management in LRS seems to be indicated. Also, recent developments in the methodology of systematic reviews are included in the present review and finally more specific physical therapy databases were searched.

\section{Objectives}

The aim of this systematic review was to assess the effectiveness of conservative treatments in the lumbosacral radicular syndrome when compared to placebo, inactive or no treatment and other forms of conservative care or surgery.

\section{Criteria for considering studies for this review}

Types of studies

Only randomised clinical trials (RCTs) published in English, Dutch, French and German languages were included. Excluded were abstracts of which full reports were not available and unpublished studies.

\section{Types of participants}

Included patients with an acute (less than 6 weeks), subacute (6-12 weeks) or chronic (12 weeks or more) lumbosacral radicular syndrome treated in a primary health care or occupational setting were included. Those patients with LRS, which focus on rarely occurring causes such as tumours and radiculitis were excluded.

Types of interventions

All types of conservative treatment such as oral medication (e.g. NSAIDs, muscle relaxants), injections, physical therapy, spinal manipulation, bed rest, traction and acupuncture were included. Comparisons investigated were: (1) conservative treatment versus placebo, inactive or no treatment, (2) conservative treatment versus other type(s) of conservative treatment, and (3) conservative treatment versus surgery.

Types of outcome measures

Studies were included that used at least one of the four primary outcome measures that we considered to be the most important [36]; that is an outcome of symptoms (e.g. pain), overall improvement (e.g. proportion of patients recovered, subjective improvement of symptoms), function (e.g. Roland Disability Questionnaire for sciatica, Oswestery Scale), and return to work (e.g. days off work).

Outcomes of physiological or physical examinations (e.g. range of motion, spinal flexibility, degrees of straight leg raising or muscle strength), quality of life (e.g. SF-36, Nottingham Health Profile, Sickness Impact Profile) and psycho-social outcomes (anxiety, depression, pain behaviour) were considered as secondary outcomes. Other outcomes such as medical consumption and side effects were also considered.

The treatment outcomes were assessed at short-term follow-up (less than 3 months after randomisation), at intermediate follow-up (between 3 months and 1 year after randomisation) and at long-term follow-up (1 year or more after randomisation).

\section{Search strategy for identification of studies}

We used the search strategy recommended by the Editorial Board of the Cochrane Collaboration Back Review Group [36] The highly sensitive search strategies for retrieval of studies of controlled trials [30] were run in conjunction with a specific search for the lumbosacral radicular syndrome and conservative treatments. All relevant studies meeting our inclusion criteria were identified by: (1) searches in electronic database: PUBMED-MEDLINE (from 1966 to May 2004), EMBASE (from 1980 to May 2004), Cochrane Central Register of Controlled Trials (CENTRAL, 1800-2004) [10], Cinahl (from 1982 to May 2004), PsycINFO (psychological interventions from 1984 to May 2004), and PEDro (Physiotherapy Evidence Database to May 2004), and (2) screening the references of all studies selected from the electronic databases searches and relevant reviews.

\section{Methods}

Study selection

One reviewer (PL) performed the search strategy. Two reviewers ( $\mathrm{PL}$ and $\mathrm{TvO}$ ) independently selected the studies to be included in the systematic review. First, they screened the title, keywords and abstract for eligibility. Secondly, they assessed the full text papers to ascertain whether the study met the inclusion criteria regarding design, subjects, and intervention. Disagreements on inclusion are resolved by discussion, or through arbitration by a third reviewer (AV). 
Methodological quality assessment

Two reviewers (PL and RO) independently assessed the methodological quality (MQ), using the Delphi list [38]. The Delphi list contains nine items relevant for the internal validity of each of the assessed articles. Each item was rated as 'yes', 'no', or 'don't know' (insufficient or no information presented). Equal weights were applied that resulted in a total score of each RCT, by adding the 'Yes' scores (range 0-9). A high quality (HQ) RCT was defined as a study that had a positive score (Yes) on five or more Delphi criteria. Disagreements were solved in a consensus meeting. When disagreements persisted a third reviewer (AV) was consulted.

Clinical relevance

Two reviewers (WP and BK) independently assessed the clinical relevance (CR). The Cochrane Collaboration Back Review Group recommends the following five questions used in judging clinical relevance [36]:

(1) Are the patients described in detail so that you can decide whether they are comparable to those you see in your own practice? (2) Are the intervention(s) and treatment setting (s) described well enough to allow you to provide the same to your own patients? (3) Were all clinically relevant outcomes measured and reported? (4) Is the size of effect clinically important? and (5) Are the likely treatment benefits worth the potential harms? Each question was rated as 'yes', 'no', or 'don't know' (insufficient or no information presented). Disagreements were solved in a consensus meeting. When disagreements persist a third reviewer (AV) was consulted. A study was considered clinical relevant if the questions 1, 2 and 3 scored 'Yes'.

\section{Data extraction}

One reviewer (PL) extracted the data of the included RCTs. In cases of uncertainly about the data extracted from the individual trials a second reviewer (AV) was consulted.

Data analysis

The inter-observer reliability of the quality assessments was calculated using Kappa $(<0.5$ means a poor level of agreement between assessors; between 0.5 and 0.7 a moderate level of agreement, and $>0.7$ a high level of agreement) [19].

The data of the effect measurements reported in each study are presented as relative risks (RR) with corresponding 95\% confidence intervals for dichotomous data and effect sizes (ES) and 95\% confidence intervals for continuous data.
Quantitative analysis

Statistical pooling (meta-analysis) of the study outcomes (using a random effect model) will be performed if the studies are considered clinically homogeneous.

Qualitative analysis

If the studies are considered to be heterogeneous, the factors possibly underlying this phenomenon are considered. The results are summarised using a rating system that consists of following five levels of scientific evidence which have been used in previous systematic reviews in the field of back pain, based on the overall quality and the outcome of the studies [36]: (1) strong evidence-consistent findings in multiple high quality RCTs, (2) moderate evidence-consistent findings among multiple low quality RCTs and/or one high quality RCT, (3) limited evidence-one low quality RCT, (4) conflicting evidence-inconsistent findings among multiple RCTs and (5) no evidence-no RCTs. Consistent findings mean that $80 \%$ of the findings are in the same direction.

\section{Results}

\section{Description of studies}

The search strategy in the electronic databases selected 794 titles to be screened by two reviewers (PL and TvO). Disagreements were discussed and solved; 30 RCTs were included which were published in English and in French. Figure 1 shows the flow chart of the selection process.

The 30 publications included in total 2,780 patients with LRS and evaluated injections $(n=14)$, traction $(n=9)$, physical therapy $(n=4)$, bed rest $(n=2)$, manipulation $(n=2)$, medication $(n=2)$ and acupuncture $(n=1)$. In 18 RCTs the sample size was small, meaning less than 30 patients in one study arm.

Methodological quality of the included studies

The two reviewers (PL and RO) agreed on 230 of the 270 item scores $(85.2 \%)$. The inter-observer reliability of the MQ assessment (kappa $=0.70)$ was moderate. Disagreements were solved in consensus for most cases, the third reviewer $(\mathrm{AV})$ had to decide five times (1.8\%). Detailed results of the MQ assessment are presented in Tables 1, 2, $3,4,5,6$ and 7 . Twelve studies $(40.0 \%)$ of the 30 included RCTs were considered to be of high quality. The overall MQ score ranged from two to nine out of maximal nine points. The following are the most prevalent shortcomings of the studies concerned: no adequate description of 
Fig. 1 Flow chart of the selection process

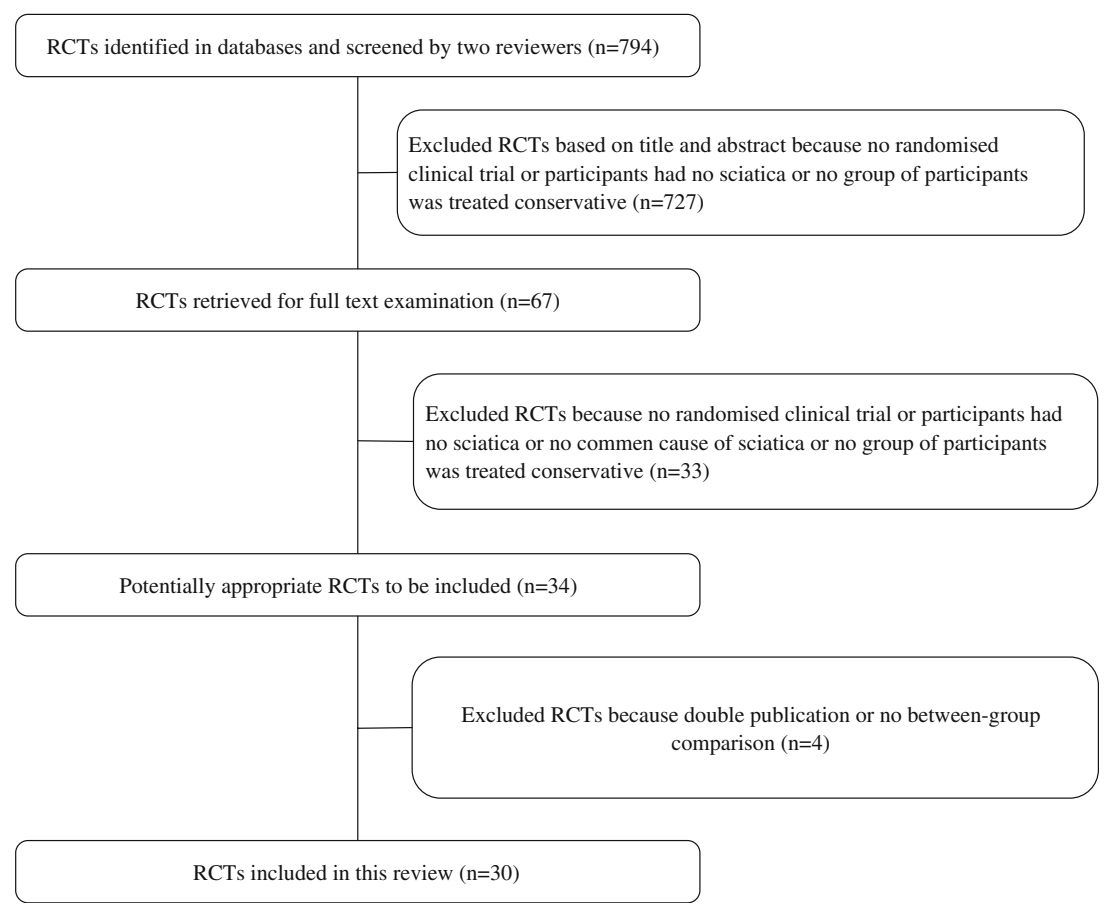

treatment allocation concealment $(n=27)$, no attempt to blind the care provider $(n=26)$ or the analysis did not include an intention-to-treat analysis $(n=23)$.

\section{Clinical relevance}

The two reviewers (WP and BK) agreed on 125 of the 150 item scores $(83.3 \%)$. The inter-observer reliability of the clinical relevance assessment $(\mathrm{kappa}=0.67)$ was moderate. Disagreements were solved in consensus for all cases. Detailed results of the clinical relevance assessment are presented in Tables 1, 2, 3, 4, 5, 6 and 7. The overall clinical relevance score ranged from 0 to 5 out of maximal 5 points. Ten studies $(33.3 \%)$ were considered clinically relevant because a 'Yes' was scored on the first three questions.

Finally, six RCTs [6, 11, 17, 33, 35, 43] were considered to be of high quality and clinically relevant. Five RCTs [6, 11, 17, 33, 35] evaluated injections and 1 RCT [43] medication.

\section{Evidence of effectiveness}

Even in subgroups according to the intervention the included RCTs were not considered clinically comparable concerning study population (e.g. underlying cause of LRS and acute, subacute and chronic patients), control treatments, duration of follow-up, and outcome measures. Because of this heterogeneity we refrained from statistical pooling and performed a qualitative analysis.

\section{Injections}

Table 1 shows the characteristics of fourteen studies that compared injection to placebo ( 9 RCTs), to no treatment (2 RCTs) and to other injections (4 RCTs).

Versus placebo

Nine studies [5, 6, 8, 11, 14, 17, 18, 29, 33] compared epidural or extradural corticosteroid injection to placebo injection. Six studies were considered high quality [6, 8, $11,17,29,33$ ] of which one study [29] did not provide any data.

In three high quality studies $[6,11,33]$ and one low quality study [14], we found no difference in pain between injection and placebo at short-term. However, in another one high quality [17] and one low quality study [5] we found an effect in pain at short-term, in favour of injection.

In three high quality studies [6, 8, 33] and one low quality study [18], we found no difference in overall improvement between injection and placebo at short-term. However, in another low quality study [14] we found an effect in improvement, in favour of injection.

Long-term effects for pain and overall improvement were not found in two high quality studies [17] and one low quality study [5]. Also, no short or long-term effects were found for disability and return to work in three high quality studies [6, 11, 17].

In conclusion, when comparing corticosteroid injections to placebo for patients with LRS we found conflicting 


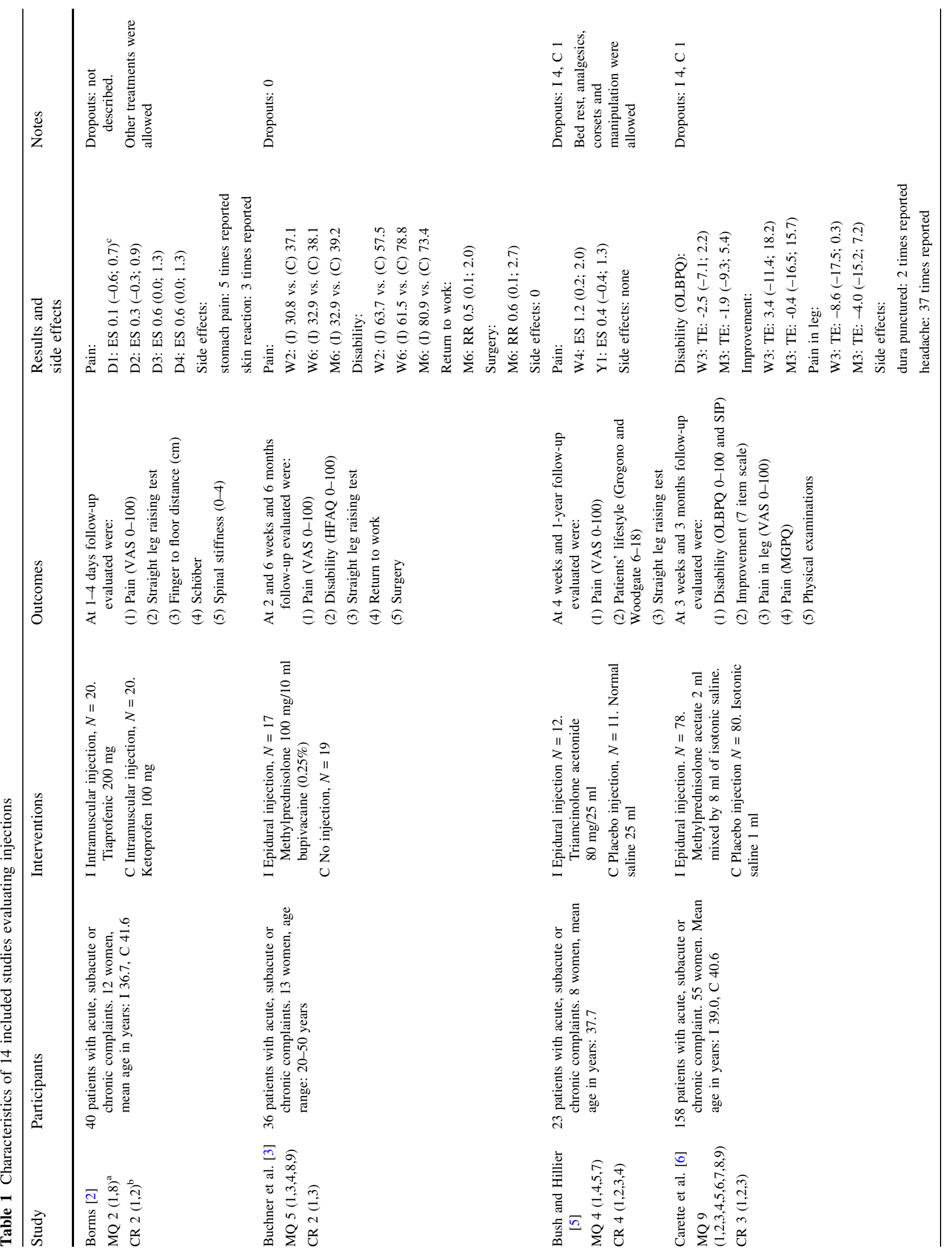




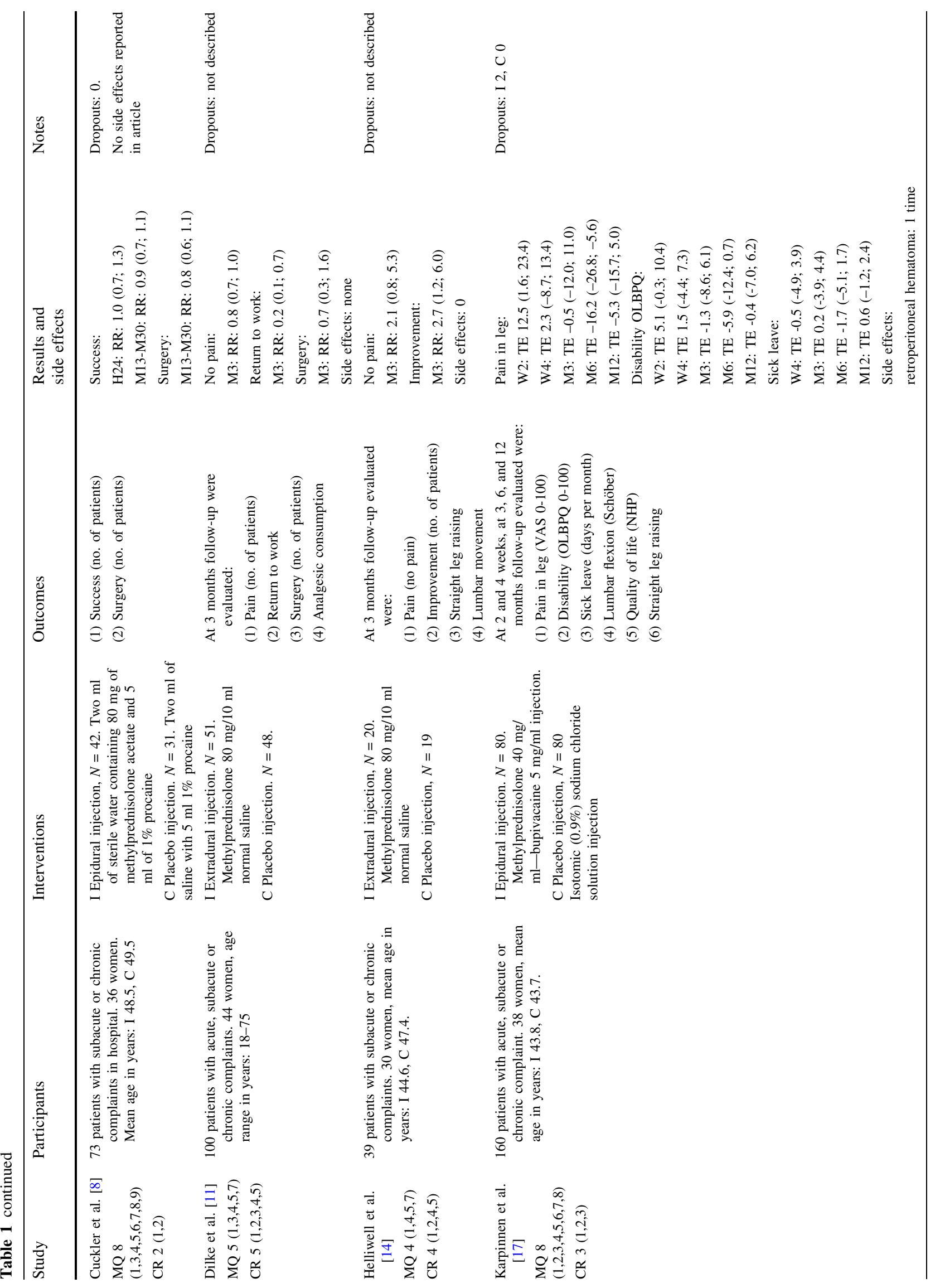




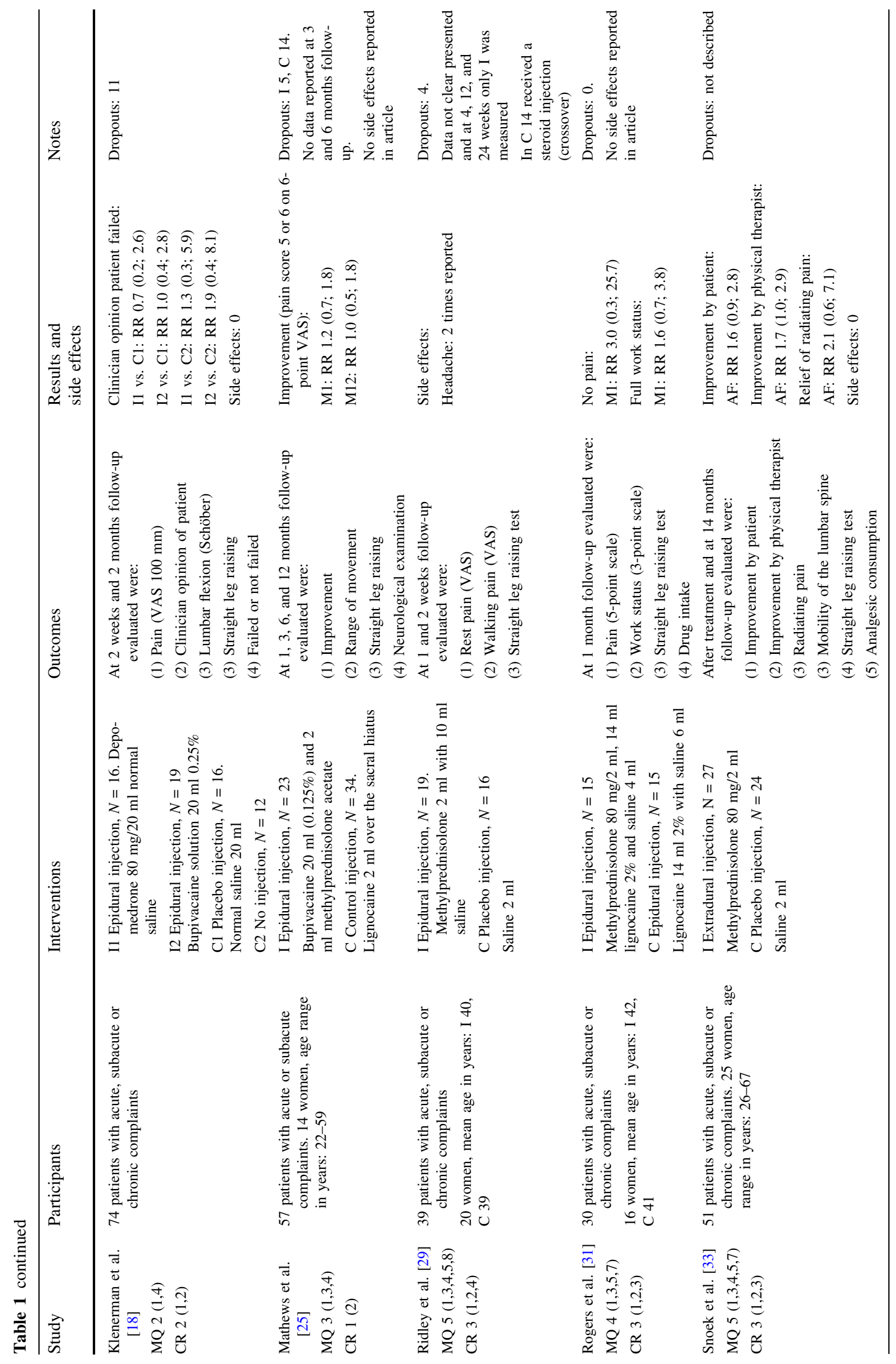




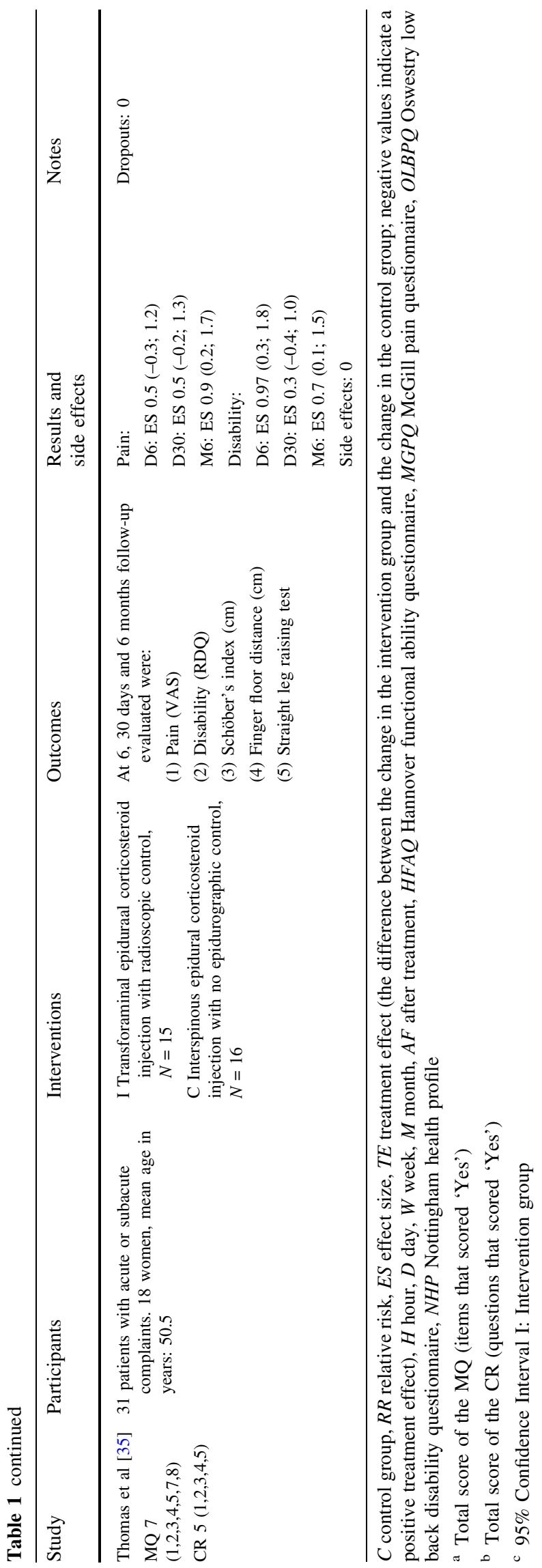

evidence regarding pain and overall improvement at shortterm follow-up and no difference (2 HQ, 1 LQ trials: strong evidence) at long-term follow-up. For disability and return to work we found no difference (3 HQ trials: strong evidence) at short and long-term follow-up.

Versus no treatment

Two studies [3, 18] compared epidural corticosteroid injection to no injection. In both studies, one of high quality [3] and one of low quality [18], we found no difference in overall improvement and return to work between groups. Therefore, when comparing corticosteroid injections to no treatment for patients with LRS we found no difference (1 LQ trial: limited evidence) regarding overall improvement at short-term follow-up and no difference (1 HQ trial: moderate evidence) regarding return to work at intermediate follow-up.

Versus other injections

Four studies $[2,25,31,35]$ compared epidural or intramuscular corticosteroid injection to an injection of a NSAID or an anaesthetic. In one high quality [35] and two low quality studies $[25,31]$ we found no difference in pain and return to work at short-term. However, in another low quality study [2] we found a difference in pain at shortterm, in favour of corticosteroid injection. In one high quality study [35] we found a difference in pain at intermediate follow-up, in favour of injection with radioscopic control. In one low quality study [25] we found no difference in pain at long-term.

In one high quality study [35] we found a difference in disability at short-term and intermediate follow-up, in favour of injection with radioscopic control.

Therefore, we conclude that there is conflicting evidence for the benefit of corticosteroid injection over an injection with a NSAID or anaesthetic regarding pain at short-term follow-up. There is moderate evidence that an injection with radioscopic control is more effective than injection without radioscopic control regarding pain at intermediate follow-up and regarding disability at short-term and intermediate follow-up for patients with LRS. No difference (2 LQ trials: moderate evidence) between injections was found regarding return to work at short-term follow-up and regarding pain at long-term follow-up.

\section{Traction}

Table 2 shows the characteristics of nine studies that compared traction to inactive/sham traction (4 RCTs) and to another conservative treatment (5 RCTs). 


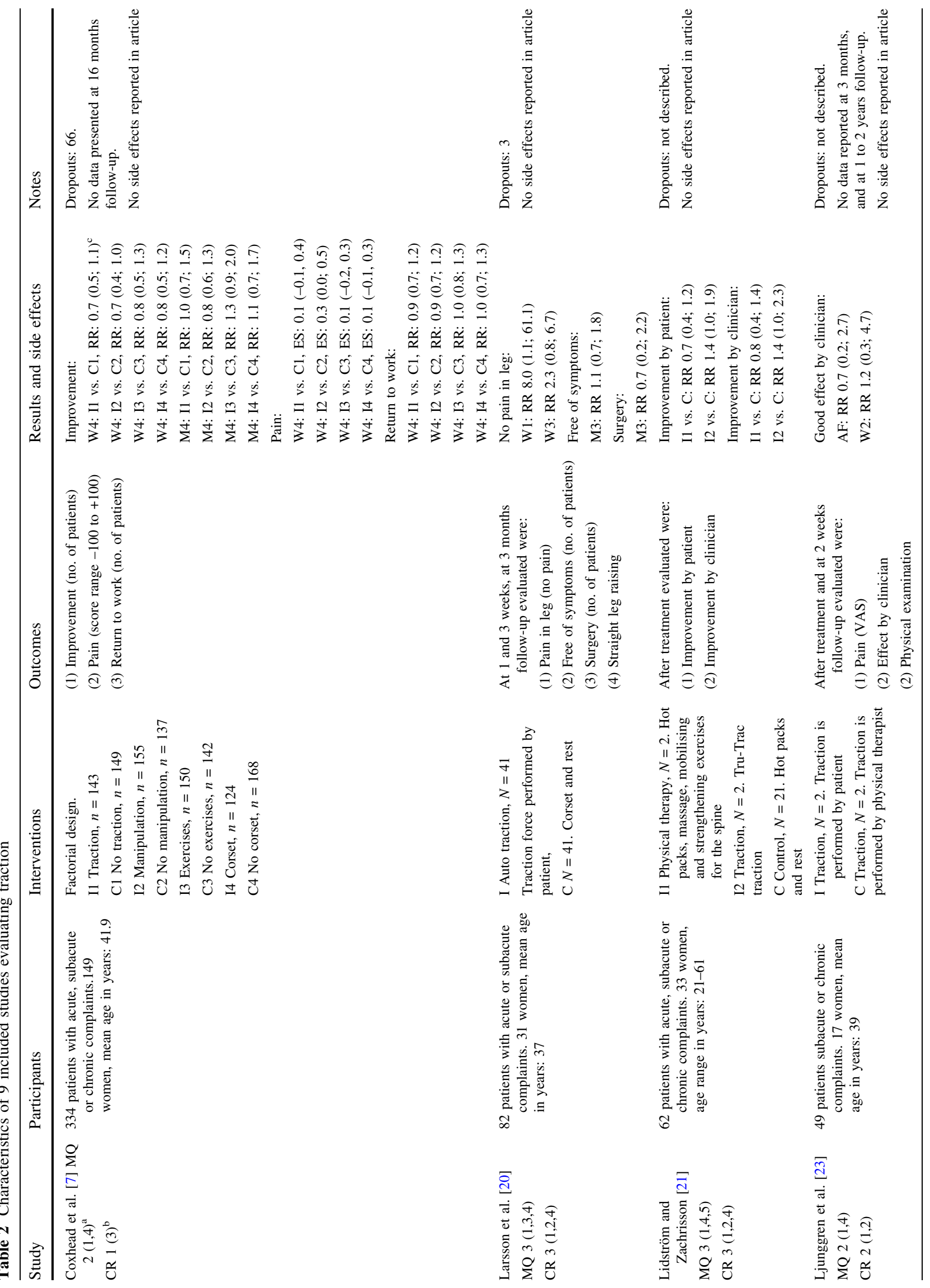




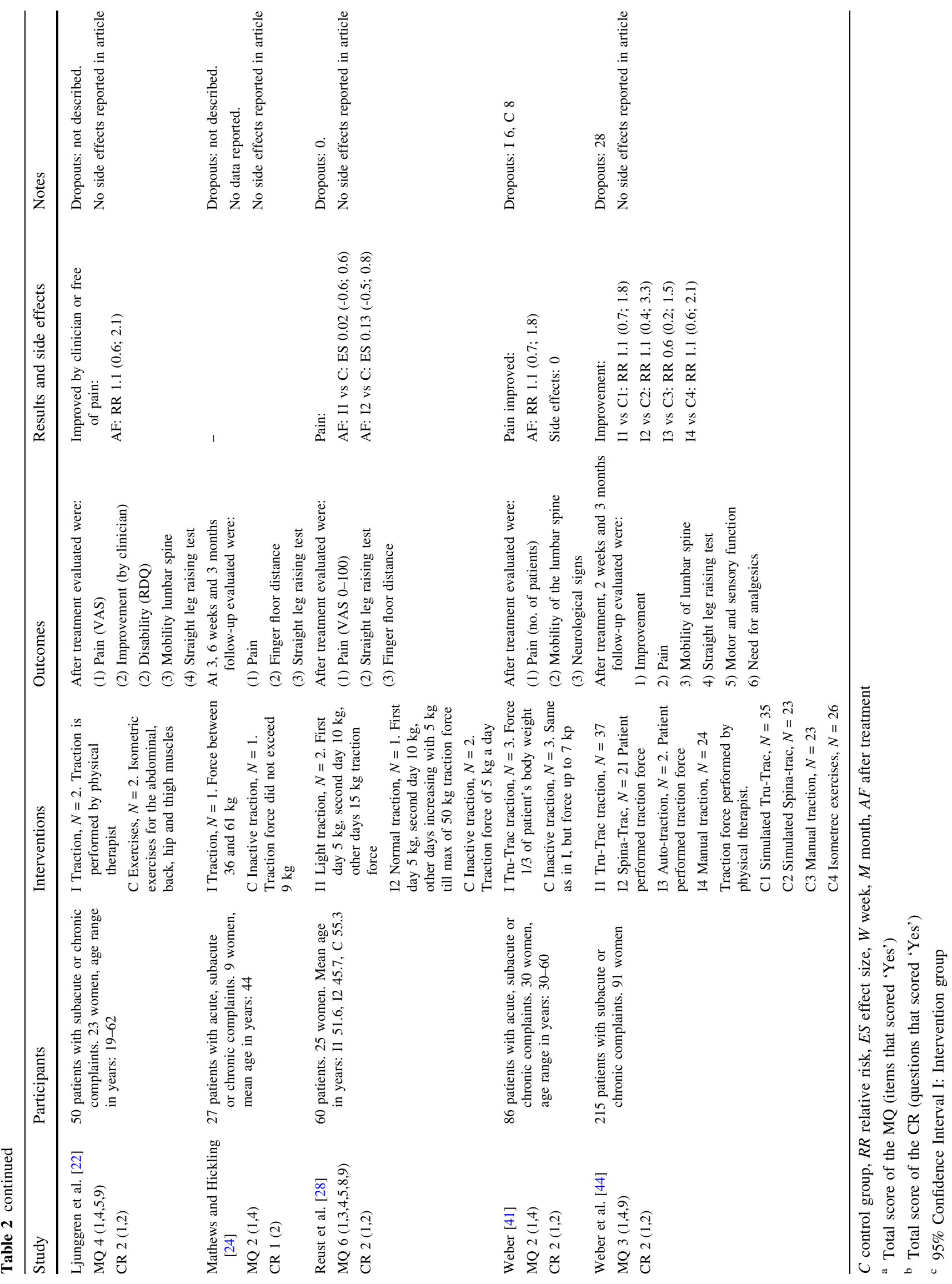


Versus inactive/sham traction

Four studies [24, 28, 41, 44] compared traction to inactive/ sham traction. One low quality study [24] did not report any data.

In one high quality [28] and one low quality studies [41] we found no difference in pain between traction and inactive/sham traction at short-term. Also, in one low quality study [44] we found no difference in improvement between groups at short-term.

Therefore, when comparing traction and inactive/sham traction for patients with LRS we found no difference (1 HQ, 2 LQ trials: moderate evidence) regarding pain and disability at short-term follow-up.

Versus other conservative care

Five studies [7, 20-23] compared traction to another conservative treatment. All five studies were considered of low quality. In one study [21] we found a difference between traction and other conservative care in overall improvement, in favour of traction. However, in three studies [7, 22, 23,] we found no difference in overall improvement between groups. In one study [7] we found no difference in pain between traction and other treatments, but in another study [20] we found a difference in pain, in favour of traction. In one study [7] we found no difference in return to work between groups.

Therefore, when comparing traction to other conservative treatments for patients with LRS we found conflicting evidence regarding improvement and pain at short-term follow-up. We found no difference (1 LQ trial: limited evidence) regarding return to work at shortterm follow-up.

\section{Physical therapy}

Table 3 shows the characteristics of four studies that compared physical therapy to inactive treatment (1 RCT), to other conservative care ( 2 RCTs) and to surgery (1 RCT).

\section{Versus inactive treatment}

In one high quality study [16] we found no difference in pain and disability at short and intermediate follow-up between the groups.

Therefore, when comparing physical therapy to inactive treatment for patients with acute LRS we found no difference (1 HQ trial: moderate evidence) regarding pain and disability at short and intermediate follow-up.
Versus other conservative care

Two low quality studies [7, 21] compared physical therapy to other conservative treatments. In these studies we found no difference in overall improvement, pain and return to work between groups.

Therefore, when comparing physical therapy to other conservative care for patients with LRS we found no difference (2 LQ trials: moderate evidence) regarding overall improvement, pain and return to work at short-term.

\section{Versus surgery}

In one low quality study [42] we found a difference in improvement at 1-year follow-up, in favour of surgery. In the same study we found no difference in improvement at 4 and 10-year follow-up between the two groups.

Therefore, we conclude there is limited evidence that surgery is more effective for patients with LRS regarding overall improvement than physical therapy at 1-year follow-up. At 4 and 10-year follow-up we found no difference (1 LQ trial: limited evidence) regarding overall improvement between surgery and physical therapy.

\section{Bed rest}

Table 4 shows the characteristics of two studies that compared bed rest to no treatment.

In one low quality study [39] we found no differences in overall improvement, pain, and disability at short-term follow-up between the groups. In one high quality study [16] we found no differences in pain, disability, at short and intermediate follow-up between the groups.

Therefore, when comparing bedrest to no treatment for patients with acute LRS we found no difference (1 HQ, 1 LQ trial: moderate evidence) regarding overall improvement at short-term follow-up and no difference (1 HQ trial: moderate evidence) regarding pain and disability at short and intermediate follow-up.

\section{Manipulation}

Table 5 shows the characteristics of two studies that compared manipulation to other conservative care (1 RCT) and to surgery (1 RCT).

Versus other conservative care

In one low quality study [7] we found no difference in overall improvement, pain and return to work between the groups. Therefore, when comparing manipulation to other 
conservative care for patients with LRS we found no difference (1 LQ trial: limited evidence) regarding overall improvement, pain and return to work at short-term follow-up.

\section{Versus chemonucleolysis}

In one low quality study [4] we found no differences in pain and disability between the groups. Therefore, when comparing manipulation to chemonucleolysis for patients with LRS we found no difference (1 LQ trial: limited evidence) regarding pain and disability at short and long-term follow-up.

\section{Medication}

Table 6 shows the characteristics of two studies that compared medication to placebo.

In one high quality study [43] we found no difference in sick leave between the groups. In one low quality study [1] we found no difference in overall improvement between the groups. Therefore, when comparing piroxicam or tizanidine to placebo for patients with acute LRS we found no difference (1 HQ, 1 LQ trial: moderate evidence) regarding overall improvement and sick leave at short-term follow-up.

\section{Acupuncture}

Table 7 shows the characteristics of a high quality study [12] that compared acupuncture to placebo.

No data were presented in this article. Therefore, we conclude that there is no evidence of the effectiveness of acupuncture for patients with LRS.

\section{Discussion}

This systematic review included 30 RCTs with a total of 2,780 patients with LRS that evaluated various conservative treatments. Twelve of the 30 included studies were of high methodological quality and 10 studies were considered clinically relevant. Based on the results of this systematic review regarding the conservative treatment of patients with LRS we conclude that:

1. At long-term there is no evidence in favour of corticosteroid injections when compared to placebo, no treatment or NSAID or anaesthetic injection, apart from conflicting evidence for short-term pain relief.
2. At short term there is no evidence in favour of traction when compared to sham traction or other conservative treatments.

3. At short term there is no evidence in favour of physical therapy compared to inactive treatment, other conservative treatments or surgery.

4. At short term there is no evidence in favour of bed rest compared to no treatment.

5. At short term there is no evidence in favour of manipulation compared to other conservative treatments or chemonucleolysis.

6. At short term there is no evidence in favour of medication compared to placebo.

7. No evidence was found regarding acupuncture.

In this review, like every review, there are risks of publication and language bias. There are indications that studies with negative results are not easily published as positive studies [9, 32]. Furthermore, relevant studies, which are registered in unknown databases may not be included. Because of our extensive search strategy this risk was considered small. Although efforts were made to find all published RCTs in restricted languages (i.e. English, Dutch, French and German), some relevant studies published in other languages might have been missed. Also, the number of non-English journals indexed in searched electronic databases is limited.

There was an overall clinical heterogeneity of the included studies. There appeared to be many differences in study populations i.e. underlying cause of LRS and acute, subacute and chronic patients), interventions, duration of follow-up and outcome measures.

It was considered clinically inappropriate to pool the results of the RCTs in the different types of conservative treatments. Therefore a qualitative analysis was performed, using the five levels of evidence [36]. Although the levels of evidence used may be considered arbitrary, it seems unlikely that a different rating system would have resulted in different conclusions. But, in this review we included studies that almost all reported no differences in outcomes between intervention and control group. When finding no differences between groups we cannot conclude 'there is evidence that the intervention is not effective or not different from the control treatment' [15]. As recommended by the Cochrane Collaboration than to conclude that there is 'no evidence for an effect'. The analyses according the five levels of evidence are useful when significant differences are reported between treatment groups. But, when no differences between groups are reported in the majority of the included studies we found it problematic to use the levels, because we cannot conclude for example: 'there is strong evidence for no evidence of an effect'. Therefore, we have chosen to conclude with statements such as: 'we found 


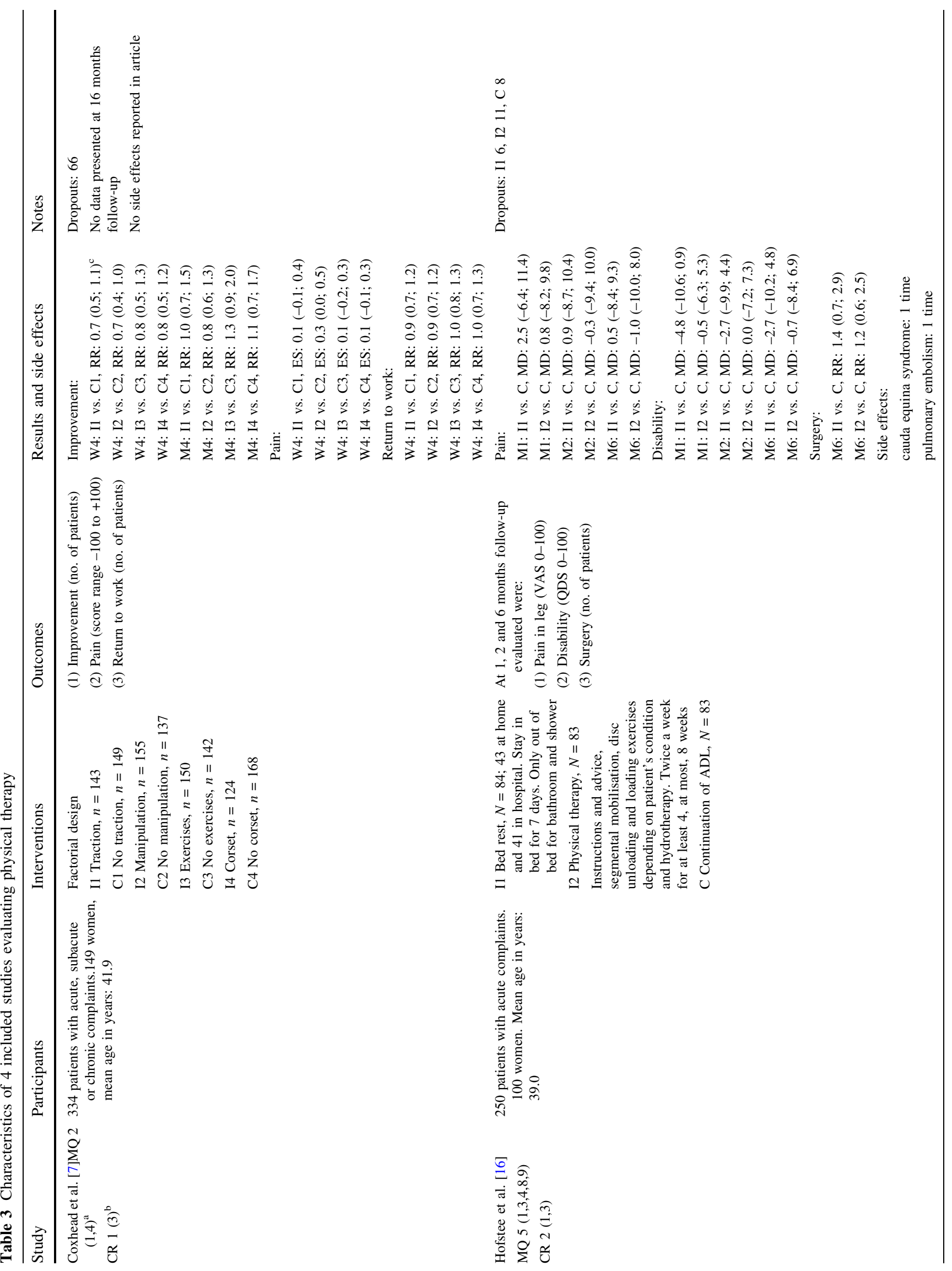




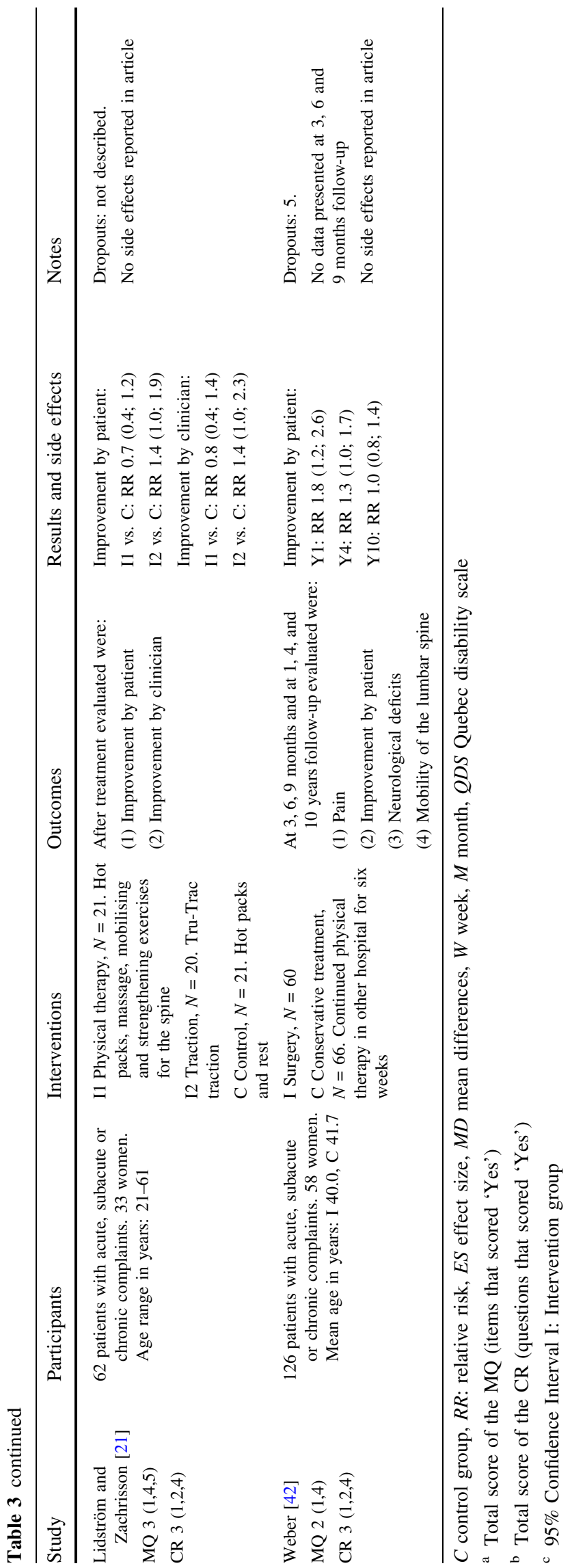

no differences between groups'. The question remains; how many trials are needed or how strong must the evidence be, to conclude that a treatment is not effective.

The methodological quality of the majority of the included studies, although improving over the past several years, was not high. Only 12 of the 30 included studies were regarded of high methodological quality. There is, however, a difficulty in blinding the patients and care provider during most conservative treatments that cannot be compared with placebo (i.e. bed rest, physical therapy, manipulation and traction).

There were studies with small sample sizes available for inclusion in this review. The number of patients in the groups was often too small to reach an adequate statistical power; only 12 studies had groups, that each consisted of over 30 patients, included.

The methodological quality might have been misclassified. Relying on the information in reported RCTs may create bias due to under reporting. But the risk of misclassification is considered small because a valid and reliable criteria list was used [37].

The conclusions of this review that included 30 trials are not all in accordance with the conclusions of the review of Vroomen et al. [39] that included 19 trials. We included more trials that evaluated corticosteroid injections and found no evidence of effect at short or at longterm follow-up. Also regarding traction we found more trials with no evidence of effect at short-term follow-up. Therefore, we do not recommend these two treatment options for patients with LRS. For the other conservative treatment options (physical therapy, bed rest, manipulation and medication) no evidence of effect was found at short-term follow-up, and long-term effects are unknown. At present there is no evidence that one type of treatment is clearly superior to others for patients with a lumbosacral radicular syndrome.

\section{Conclusions}

Implications for practice

Based on the results of this systematic review it is not recommended to use corticosteroid injections and traction because several trials indicated no evidence of an effect. Whether clinicians should prescribe physical therapy, bed rest, manipulation or medication could not be concluded from this review. For acupuncture no evidence was found.

Implications for research

There is no knowledge whether corticosteroid injection could play a role in short-term pain relief. Also unknown 


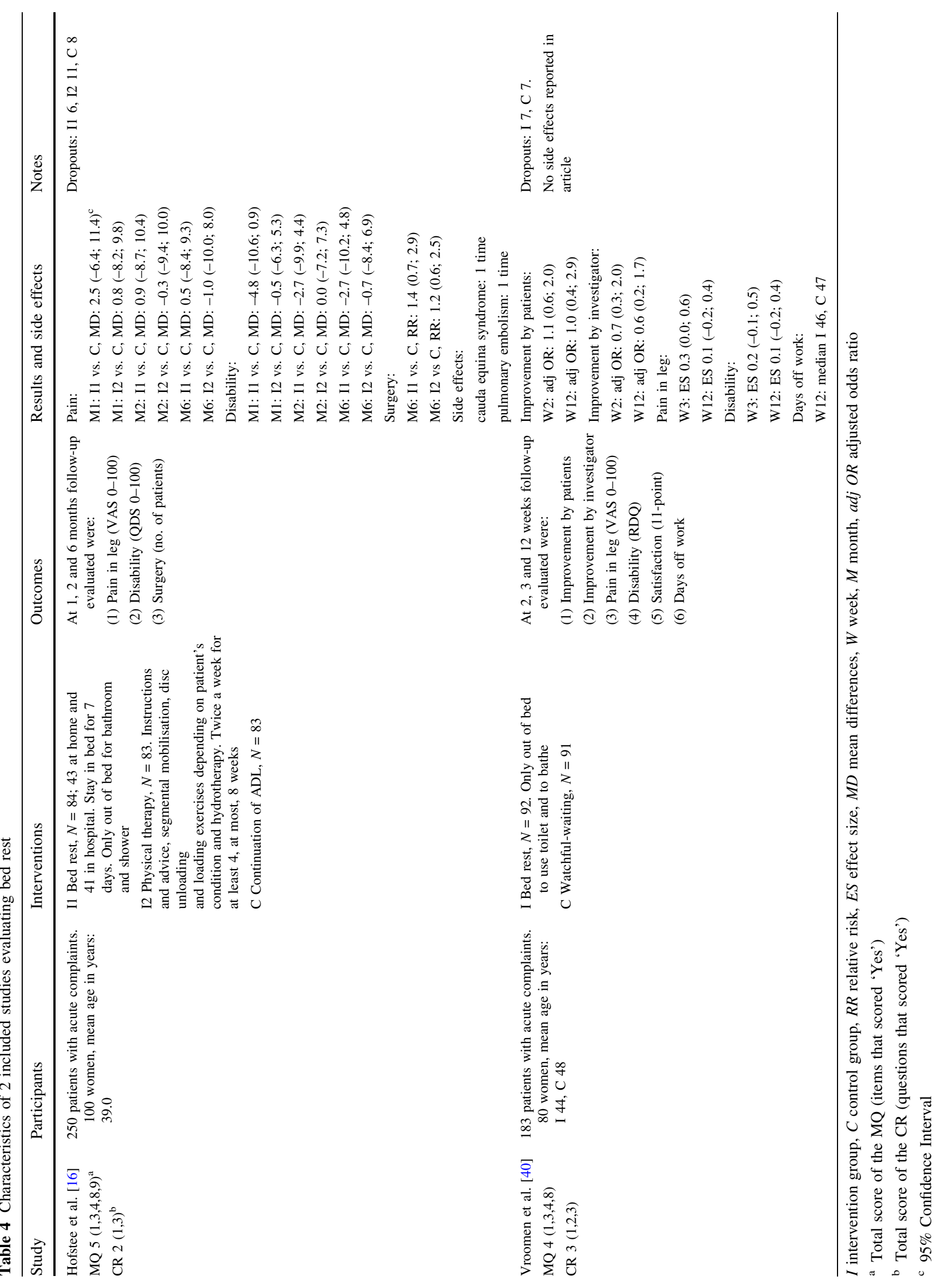




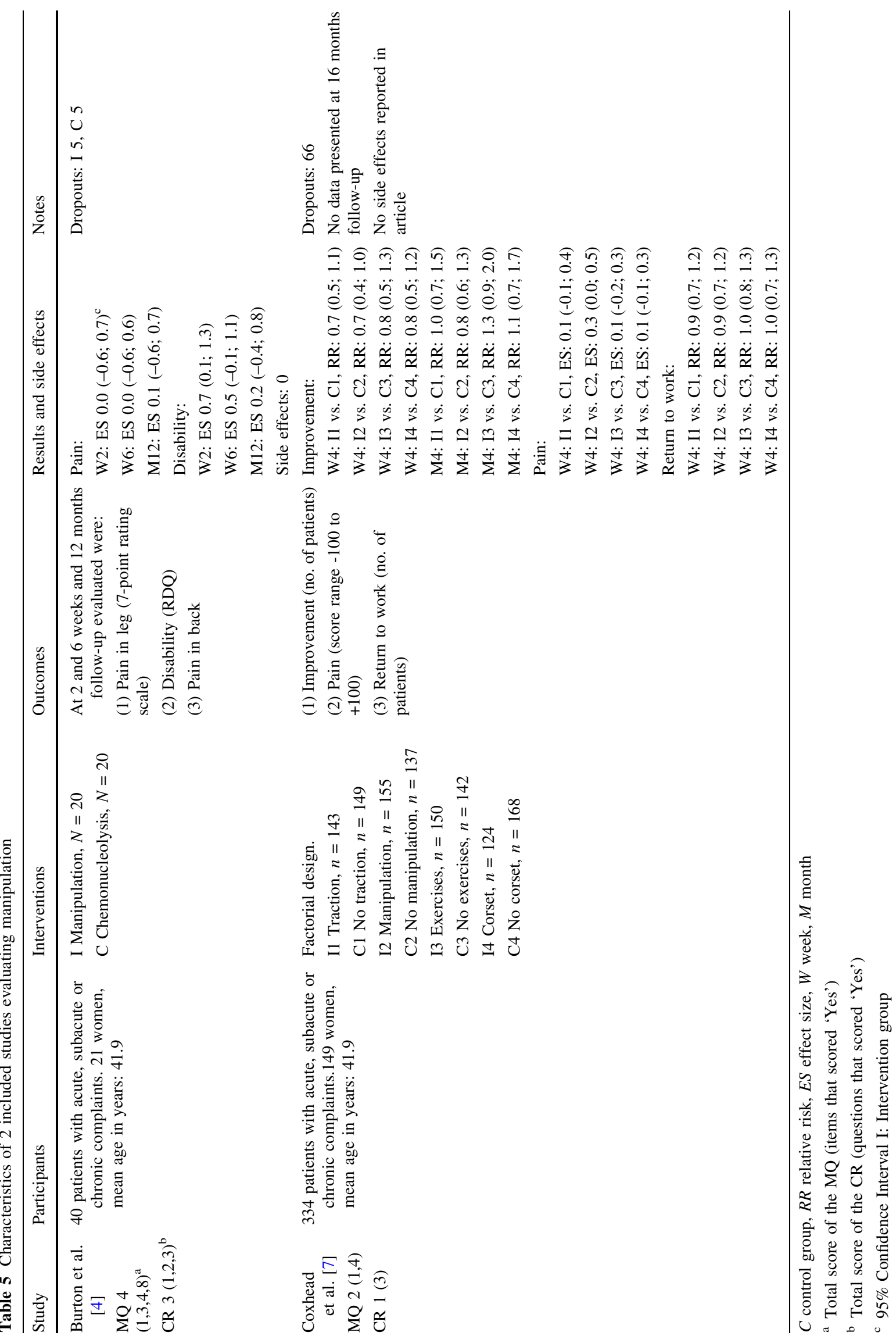


Table 6 Characteristics of 2 included studies evaluating medication

\begin{tabular}{|c|c|c|c|c|c|}
\hline Study & Participants & Interventions & Outcomes & $\begin{array}{l}\text { Results and } \\
\text { side effects }\end{array}$ & Notes \\
\hline $\begin{array}{l}\text { Berry and Hutchinson [1] } \\
\text { MQ } 4(1,3,4,8)^{\mathrm{a}} \\
\text { CR } 1(2)^{\mathrm{b}}\end{array}$ & $\begin{array}{l}59 \text { patients with } \\
\text { acute complaints, } \\
\text { age range: } \\
18-70 \text { years }\end{array}$ & $\begin{array}{l}\text { I Tizanidine (muscle } \\
\text { relaxant), } N=28 . \\
\text { Tablets } 4 \mathrm{mg}, 3 \\
\text { times daily } \\
\text { C Placebo tablets, } \\
N=31\end{array}$ & $\begin{array}{l}\text { At } 3 \text { and } 7 \text { days follow- } \\
\text { up evaluated were: } \\
\text { (1) Improvement } \\
\text { (2) Pain on movement, } \\
\text { at rest, at night (VAS } \\
0-100 \text { ) } \\
\text { (3) Restriction of } \\
\text { movement } \\
\text { (4) Consumption of } \\
\text { aspirin tablets }\end{array}$ & $\begin{array}{l}\text { Improvement: } \\
\text { D3: RR } 0.9 \\
(0.3 ; 3.0)^{\mathrm{c}} \\
\text { D7: RR } 0.8 \\
(0.5 ; 1.2)\end{array}$ & $\begin{array}{l}\text { Dropouts: not described. } \\
\text { The } 59 \text { patients were a } \\
\text { subgroup from } 112 \\
\text { patients with acute low } \\
\text { back pain } \\
\text { No side effects reported in } \\
\text { article }\end{array}$ \\
\hline $\begin{array}{l}\text { Weber et al. [43] } \\
\text { MQ } 5(1,4,5,6,7) \\
\text { CR } 3(1,2,3)\end{array}$ & $\begin{array}{l}214 \text { patients with } \\
\text { acute complaints, } \\
\text { mean age in } \\
\text { years: } 48\end{array}$ & $\begin{array}{l}\text { I Piroxicam (NSAID), } \\
\quad N=120 \\
\text { C Placebo medication, } \\
N=94\end{array}$ & $\begin{array}{l}\text { At } 1,2,3,4 \text { weeks and } \\
3 \text { and } 12 \text { months } \\
\text { follow-up evaluated } \\
\text { were: } \\
\text { (1) Pain in leg (VAS } \\
0-100 \text { ) } \\
\text { (2) Disability (RDQ) } \\
\text { (3) Sick leave }\end{array}$ & $\begin{array}{l}\text { Sick leave: } \\
\text { W4: RR } 1.0 \\
(0.8 ; 1.3)\end{array}$ & $\begin{array}{l}\text { Dropouts: } 36 \\
\text { Data not clear presented } \\
\text { No side effects reported in } \\
\text { article }\end{array}$ \\
\hline
\end{tabular}

$I$ intervention group, $C$ control group, $R R$ relative risk, $D$ day, $W$ week

a Total score of the MQ (items that scored 'Yes')

b Total score of the CR (questions that scored 'Yes')

c $95 \%$ Confidence Interval

Table 7 Characteristics of included study evaluating acupuncture

\begin{tabular}{|c|c|c|c|c|c|}
\hline Study & Participants & Interventions & Outcomes & $\begin{array}{l}\text { Results and } \\
\text { side effects }\end{array}$ & Notes \\
\hline \multirow{5}{*}{$\begin{array}{l}\text { Duplan et al. } \\
\quad[12] \\
\text { MQ } 5 \\
(1,3,4,5,7)^{\mathrm{a}} \\
\text { CR } 0(-)^{\mathrm{b}}\end{array}$} & \multirow[t]{5}{*}{$\begin{array}{l}30 \text { patients with acute complaints. } 9 \\
\text { women. Mean age in years: } 40\end{array}$} & $\begin{array}{l}\text { I Acupuncture on electrically } \\
\text { detected points, } N=15\end{array}$ & $\begin{array}{l}\text { After } 5 \text { sessions } \\
\text { evaluated were: }\end{array}$ & \multirow[t]{5}{*}{-} & $\begin{array}{l}\text { Dropouts: not } \\
\text { described }\end{array}$ \\
\hline & & \multirow[t]{4}{*}{$\begin{array}{l}\text { C Acupuncture on placebo } \\
\text { points, } N=15\end{array}$} & $\begin{array}{l}\text { (1) Duration of } \\
\text { improvement }\end{array}$ & & \multirow{4}{*}{$\begin{array}{l}\text { No side effects } \\
\text { reported in article }\end{array}$} \\
\hline & & & $\begin{array}{l}\text { (2) Improvement in } \\
\text { decubitis }\end{array}$ & & \\
\hline & & & $\begin{array}{l}\text { (3) Improvement } \\
\text { after } 10 \text { min standing }\end{array}$ & & \\
\hline & & & (4) Use of analgesics & & \\
\hline
\end{tabular}

$I$ intervention group, $C$ control group

a Total score of the MQ (items that scored 'Yes')

b Total score of the CR (questions that scored 'Yes')

are the long-term effects of traction, physical therapy, bed rest, manipulation or medication. We recommend high quality RCTs of sufficient sample size with longterm follow-up concerning physical therapy, manipulation or medication for patients with LRS. The outcome measures should include overall improvement, patients' satisfaction, severity of pain in the leg, functional health status, quality of health status, return to work and side effects.

\section{References}

1. Berry H, Hutchinson DR (1988) Tizanidine and ibuprofen in acute low-back pain: results of a double-blind multicentre study in general practice. J Int Med Res 16:83-91

2. Borms T (1988) Comparison of injectable formulations of tiaprofenic acid and ketoprofen in acute lumbar sciatica. Singleblind randomised trial. Drugs 35(Suppl 1):85-7

3. Buchner M, Zeifang F, Brocai DR, Schiltenwolf M (2000) Epidural corticosteroid injection in the conservative management of sciatica. Clin Orthop 375:149-56 
4. Burton AK, Tillotson KM, Cleary J (2000) Single-blind randomised controlled trial of chemonucleolysis and manipulation in the treatment of symptomatic lumbar disc herniation. Eur Spine J 9:202-207

5. Bush K, Hillier S (1991) A controlled study of caudal epidural injections of triamcinolone plus procaine for the management of intractable sciatica. Spine 16:572-575

6. Carette S, Leclaire R, Marcoux S, Morin F, Blaise GA, St-Pierre A, Truchon R, Parent F, Levesque J, Bergeron V, Montminy P, Blanchette C (1997) Epidural corticosteroid injections for sciatica due to herniated nucleus pulposus. $\mathrm{N}$ Engl $\mathrm{J}$ Med 336:1634-1640

7. Coxhead CE, Inskip H, Meade TW, North WR, Troup JD (1981) Multicentre trial of physiotherapy in the management of sciatic symptoms. Lancet 1:1065-1068

8. Cuckler JM, Bernini PA, Wiesel SW, Booth RE Jr, Rothman RH, Pickens GT (1985) The use of epidural steroids in the treatment of lumbar radicular pain. A prospective, randomized, doubleblind study. J Bone Joint Surg Am 67:63-66

9. Dickersin K, Rennie D (2003) Registering clinical trials. Jama 290:516-523

10. Dickersin K, Manheimer E, Wieland S, Robinson KA, Lefebvre C, McDonald S (2002) Development of the cochrane collaboration's CENTRAL register of controlled clinical trials. Eval Health Prof 25:38-64

11. Dilke TF, Burry HC, Grahame R (1973) Extradural corticosteroid injection in management of lumbar nerve root compression. $\mathrm{Br}$ Med J 2:635-637

12. Duplan B, Cabanel G, Piton JL, Grauer JL, Phelip X (1983) Acupuncture et lombosciatique a la phase aigue. Etude en double aveugle de trente cas (Acupuncture and sciatica in the acute phase. Double-blind study of 30 cases) . Sem Hop 59:3109-3114

13. Health Council of the Netherlands (1999) Management of the lumbosacral radicular syndrome (sciatica). The Hague, publication no. $1999 / 18$

14. Helliwell M, Robertson JC, Ellis RM (1985) Outpatient treatment of low back pain and sciatica by a single extradural corticosteriod injection. Br J Clin Pract 39:228-231

15. Higgins JPT, Green S (eds) (2005) Cochrane handbook for systematic reviews of interventions 4.2.5 (updated May 2005). In: The Cochrane Library, Issue 3. Wiley, Chichester

16. Hofstee DJ, Gijtenbeek JM, Hoogland PH, van Houwelingen HC, Kloet A, Lotters F, Tans JT (2002) Westeinde sciatica trial: randomized controlled study of bed rest and physiotherapy for acute sciatica. J Neurosurg 96:45-49

17. Karppinen J, Malmivaara A, Kurunlahti M, Kyllonen E, Pienimaki T, Nieminen P, Ohinmaa A, Tervonen O, Vanharanta $\mathrm{H}$ (2001) Periradicular infiltration for sciatica: a randomized controlled trial. Spine 26:1059-1067

18. Klenerman L, Greenwood R, Davenport HT, White DC, Peskett S (1984) Lumbar epidural injections in the treatment of sciatica. Br J Rheumatol 23:35-38

19. Landis JR, Koch GG (1977) An application of hierarchical kappa-type statistics in the assessment of majority agreement among multiple observers. Biometrics 33:363-374

20. Larsson U, Choler U, Lidstrom A, Lind G, Nachemson A, Nilsson B, Roslund J (1980) Auto-traction for treatment of lumbagosciatica. A multicentre controlled investigation. Acta Orthop Scand 51:791-798

21. Lidström A, Zachrisson M (1970) Physical therapy on low back pain and sciatica. An attempt at evaluation. Scand J Rehabil Med 2:37-42

22. Ljunggren AE, Weber H, Larsen S (1984) Autotraction versus manual traction in patients with prolapsed lumbar intervertebral discs. Scand J Rehabil Med 16:117-124
23. Ljunggren AE, Walker L, Weber H, Amundsen T (1992) Manual traction versus isometric exercises in patients with herniated intervertebral lumbar discs. Physiother Theory Pract $8: 207-213$

24. Mathews JA, Hickling J (1975) Lumbar traction: a double-blind controlled study for sciatica. Rheumatol Rehabil 14:222-225

25. Mathews JA, Mills SB, Jenkins VM, Grimes SM, Morkel MJ, Mathews W, Scott CM, Sittampalam Y (1987) Back pain and sciatica: controlled trials of manipulation, traction, sclerosant and epidural injections. Br J Rheumatol 26:416-423

26. Mens JMA, Chavannes AW, Koes BW, Lubbers WJ, Ostelo RWJG, Spinnewijn WEM, Kolnaar BGM (2005) NHG-Standaard lumbosacraal radiculair syndroom (NHG-guideline lumbosacral radicular syndrome). Huisarts en Wetenschap 48:171-178

27. Ostelo RWJG, de Vet HCW, van Tulder MW, Kerckhoffs MR, Leffers P, Wadell G (2002) Rehabilitation after lumbar disc surgery (Protocol for a cochrane review), The Cochrane Library

28. Reust P, Chantraine A, Vischer TL (1988) Traitement par tractions mecaniques des lombosciatalgies avec ou sans deficit neurologique. Une etude en "double aveugle" (Treatment of lumbar sciatica with or without neurological deficit using mechanical traction. A double-blind study). Schweiz Med Wochenschr 118:271-274

29. Ridley MG, Kingsley GH, Gibson T, Grahame R (1988) Outpatient lumbar epidural corticosteroid injection in the management of sciatica. Br J Rheumatol 27:295-299

30. Robinson KA, Dickersin K (2002) Development of a highly sensitive search strategy for the retrieval of reports of controlled trials using PubMed. Int J Epidemiol 31:150-153

31. Rogers P, Nash T, Schiller D, Norman J (1992) Epidural steriods for sciatica. Pain Clin 5:67-72

32. Schork MA (2003) Publication bias and meta analysis. J Hypertens 21:243-245

33. Snoek W, Weber H, Jorgensen B (1977) Double blind evaluation of extradural methyl prednisolone for herniated lumbar discs. Acta Orthop Scand 48:635-641

34. Stam J (1996) Consensus over diagnostiek en behandeling van het lumbosacrale radiculaire syndroom (Consensus in diagnosing and treatment of the lumbosacral radicular syndrome). Ned Tijdschr Geneeskd 140:2621-2627

35. Thomas E, Cyteval C, Abiad L, Picot MC, Taourel P, Blotman F (2003) Efficacy of transforaminal versus interspinous corticosteroid injectionin discal radiculalgia - a prospective, randomised, double-blind study. Clin Rheumatol 22:299-304

36. Van Tulder M, Furlan A, Bombardier C, Bouter L (2003) Updated method guidelines for systematic reviews in the cochrane collaboration back review group. Spine 28:1290-1299

37. Verhagen AP, de Vet HC, de Bie RA, Boers M, van den Brandt PA (2001) The art of quality assessment of RCTs included in systematic reviews. J Clin Epidemiol 54:651-654

38. Verhagen AP, de Vet HC, de Bie RA, Kessels AG, Boers M, Bouter LM, Knipschild PG (1998) The Delphi list: a criteria list for quality assessment of randomized clinical trials for conducting systematic reviews developed by Delphi consensus. J Clin Epidemiol 51:1235-1241

39. Vroomen PC, de Krom MC, Wilmink JT, Kester AD, Knottnerus JA (1999) Lack of effectiveness of bed rest for sciatica. N Eng J Med 340:418-423

40. Vroomen PC, de Krom MC, Slofstra PD, Knottnerus JA (2000) Conservative treatment of sciatica: a systematic review. J Spinal Disord 13:463-469

41. Weber H (1973) Traction therapy in sciatica due to disc prolapse (does traction treatment have any positive effect on patients suffering from sciatica caused by disc prolapse)? J Oslo City Hosp 23:167-176 
42. Weber H (1983) Lumbar disc herniation. A controlled, prospective study with ten years of observation. Spine 8:131-140

43. Weber H, Holme I, Amlie E (1993) The natural course of acute sciatica with nerve root symptoms in a double-blind placebocontrolled trial evaluating the effect of piroxicam. Spine 18:1433-1438
44. Weber H, Ljunggren AE, Walker L (1984) Traction therapy in patients with herniated lumbar intervertebral discs. J Oslo City Hosp 34:61-70 